\title{
BMJ Open A systematic review of the predictors of health service utilisation by adults with mental disorders in the UK
}

\author{
Conal D Twomey, ${ }^{1}$ David S Baldwin, ${ }^{2}$ Maren Hopfe, ${ }^{3,4}$ Alarcos Cieza ${ }^{5,6,7}$
}

To cite: Twomey CD, Baldwin DS, Hopfe M, et al. A systematic review of the predictors of health service utilisation by adults with mental disorders in the UK. BMJ Open 2015;5:e007575. doi:10.1136/bmjopen-2015007575

- Prepublication history for this paper is available online. To view these files please visit the journal online (http://dx.doi.org/10.1136/ bmjopen-2015-007575).

Received 2 January 2015 Revised 31 March 2015 Accepted 14 May 2015

CrossMark

For numbered affiliations see end of article.

Correspondence to

Conal D Twomey;

c.twomey@soton.ac.uk

\section{ABSTRACT}

Objectives: To identify variables that predict health service utilisation (HSU) by adults with mental disorders in the UK, and to determine the evidence level for these predictors.

Design: A narrative synthesis of peer-reviewed studies published after the year 2000. The search was conducted using four databases (ie, PSycINFO, CINAHL Plus with full text, MEDLINE and EMBASE) and completed on 25 March 2014.

Setting: The majority of included studies were set in health services across primary, secondary, specialist and inpatient care. Some studies used data from household and postal surveys.

Participants: Included were UK-based studies that predicted HSU by adults with mental disorders. Participants had a range of mental disorders including psychotic disorders, personality disorders, depression, anxiety disorders, eating disorders and dementia.

Primary outcome: A wide range of HSU outcomes were examined, including general practitioner (GP) contacts, medication usage, psychiatrist contacts, psychotherapy attendances, inpatient days, accident and emergency admissions and 'total HSU'.

Results: Taking into account study quality, 28 studies identified a range of variables with good preliminary evidence supporting their ability to predict HSU. Of these variables, comorbidity, personality disorder, age (heterogeneous age ranges), neurotic symptoms, female gender, a marital status of divorced, separated or widowed, non-white ethnicity, high previous HSU and activities of daily living, were associated with increased HSU. Moreover, good preliminary evidence was found for associations of accessing a primary care psychological treatment service and medication use with decreased HSU.

Conclusions: The findings can inform decisions about which variables might be used to derive mental health clusters in 'payment by results' systems in the UK. The findings also support the need to investigate whether combining broad diagnoses with care pathways is an effective method for mental health clustering, and the need for research to further examine the association between mental health clusters and HSU.

\section{Strengths and limitations of this study}

- The review was limited to UK studies, meaning the list of identified variables is not exhaustive and the findings may not be applicable to services in other countries.

- There was wide heterogeneity in the operationalisation of health service utilisation (HSU) by included studies, which limits the validity of comparisons across studies. Addressing this issue, the operationalisation of HSU in included studies was documented in considerable detail (table 1).

- The study benefits from its use of structured checklists for assessments of study quality.

- The majority of literature searching was undertaken by one study author. However, in order to minimise bias and error, $20 \%$ of abstracts were independently screened by another author.

\section{INTRODUCTION}

Many stakeholders with differing needs are involved in the delivery of public health services. Patients seek the best obtainable care, providers aim to deliver optimal care but also strive for self-regulation and autonomy, and policymakers need to balance meeting high public demand with controlling health service expenditure. ${ }^{1}$ To meet these differing needs, fair and efficient health service payment systems are required. Contemporary, 'activitybased' payment systems aim to achieve this fairness and efficiency by financially incentivising competing providers to treat more patients, cut costs and reduce waiting list times. ${ }^{2}$

In typical activity-based payment systems, resources are allocated towards distinct patient 'clusters' (or groups). These clusters are comprised of patients with similar clinical characteristics and expected health service utilisation (HSU) patterns. ${ }^{3}$ Each patient treated by a health service provider is assigned to a specific cluster based on collected information about a range of 'case-mix' variables (eg, diagnosis, comorbidity, age) which are associated 
Table 1 Observational studies of HSU ( $n=17)$

\begin{tabular}{|c|c|c|c|c|c|c|c|c|c|c|}
\hline \multirow[b]{2}{*}{ Study } & \multirow[b]{2}{*}{ Design } & \multirow[b]{2}{*}{ Data source } & \multicolumn{4}{|l|}{ Participants } & \multirow[b]{2}{*}{ Q ST } & \multirow[b]{2}{*}{ HSU outcomes } & \multirow[b]{2}{*}{ Predictors of increased HSU } & \multirow{2}{*}{$\begin{array}{l}\text { Not predictive of } \\
\text { increased HSU }\end{array}$} \\
\hline & & & Composition & $\mathbf{N}$ & Age & Per cent $f$ & & & & \\
\hline Button et $a^{P^{6}}$ & Cohort & $\begin{array}{l}\text { NHS eating disorders } \\
\text { clinic }\end{array}$ & $\begin{array}{l}\text { Patients with eating } \\
\text { disorder }\end{array}$ & 147 & $\mathrm{p}$ & 96 & 9 & Total HSU & - & $\begin{array}{l}\text { Type of eating } \\
\text { disorder diagnosis }\end{array}$ \\
\hline Byford et $a^{P^{7}}$ & Cohort & $\begin{array}{l}\text { NHS primary care } \\
\text { database }\end{array}$ & $\begin{array}{l}\text { Patients with } \\
\text { depression }\end{array}$ & 88935 & $\begin{array}{l}44.4 \\
(S D=16.75)\end{array}$ & 68 & 18 & $\begin{array}{l}\text { A\&E attendances } \\
\text { - GP phone calls } \\
\text { GP visits } \\
\text { - Inpatient days } \\
\text { Medication usage } \\
\text { Other specialist } \\
\text { contacts } \\
\text { Psychiatrist contacts } \\
\text { - Psychologist contacts }\end{array}$ & $\begin{array}{l}\text { Non-remission (after } \\
\text { antidepressant treatment) }\end{array}$ & $\begin{array}{l}\text { Remission (after } \\
\text { antidepressant } \\
\text { treatment) }\end{array}$ \\
\hline Chollet et $a^{88}$ & Cohort & $\begin{array}{l}\text { NHS primary care } \\
\text { database }\end{array}$ & Patients with GAD & 29131 & $\begin{array}{l}48.5 \\
(S D=17.5)\end{array}$ & 67 & 18 & Total HSU & $\begin{array}{l}\text { Aged } 31-49 \\
\text { Aged } 50-64 \\
\text { High previous HSU } \\
\text { High previous medication use } \\
\text { - Male } \\
\text { Two comorbidities }\end{array}$ & $\begin{array}{l}\text { Aged } 18-30 \\
\text { Aged }>65 \\
\text { Lower previous HSU } \\
\text { Lower previous } \\
\text { medication use } \\
\text { Female; No, one, or } \\
\text { three comorbidities }\end{array}$ \\
\hline Coid et $a^{R^{9}}$ & Cross-sectional & $\begin{array}{l}\text { Adult Psychiatric } \\
\text { Morbidity Survey }\end{array}$ & $\begin{array}{l}\text { UK residents (some } \\
\text { with } \mathrm{BPD} \text { ) }\end{array}$ & 8397 & $\begin{array}{l}16-74 \\
\text { (M not } \\
\text { stated) }\end{array}$ & 53 & 18 & $\begin{array}{l}\text { - Community psychiatric } \\
\text { nurse contacts } \\
\text { - Counsellor contacts } \\
\text { - GP contacts for } \\
\text { psychological problems } \\
\text { - Psychiatric inpatient } \\
\text { admission } \\
\text { - Psychiatrist contacts } \\
\text { - Total HSU }\end{array}$ & - Diagnosis of BPD & - No diagnosis of BPD \\
\hline Coid et $a a^{\beta 0}$ & Cross-sectional & $\begin{array}{l}\text { Adult Psychiatric } \\
\text { Morbidity Survey }\end{array}$ & $\begin{array}{l}\text { UK residents with a } \\
\text { PD }\end{array}$ & 626 & $\begin{array}{l}16-74 \\
\text { (M not } \\
\text { stated) }\end{array}$ & 56 & 17 & $\begin{array}{l}\text { - Community psychiatric } \\
\text { nurse contacts } \\
\text { - Counsellor contacts } \\
\text { GP contacts for } \\
\text { psychological problems } \\
\text { - Medication usage } \\
\text { - Psychiatric inpatient } \\
\text { admission } \\
\text { - Psychiatrist contacts }\end{array}$ & $\begin{array}{l}\text { Cluster A, B and C: PD } \\
\text { diagnoses } \\
\text { Comorbid mental disorder and } \\
\text { substance abuse }\end{array}$ & - No comorbidity \\
\hline Cooper et $a^{\beta 1}$ & Cross-sectional & $\begin{array}{l}\text { Adult Psychiatric } \\
\text { Morbidity Survey }\end{array}$ & $\begin{array}{l}\text { UK residents (some } \\
\text { with CMPs) }\end{array}$ & 7461 & $\begin{array}{l}16+(M \text { not } \\
\text { stated })\end{array}$ & 51 & 18 & $\begin{array}{l}\text { PCT attendance } \\
\text { GP contact for } \\
\text { psychological problems } \\
\text { Medication usage }\end{array}$ & $\begin{array}{l}\text { Aged }>35 \\
\text { ADLs } \\
\text { Widowed/divorced/separated } \\
\text { Elevated neurotic symptoms } \\
\text { Female } \\
\text { - Non-white ethnicity }\end{array}$ & $\begin{array}{l}\text { Aged <35 } \\
\text { No ADLs } \\
\text { Marital status other } \\
\text { than widowed/ } \\
\text { divorced/separated } \\
\text { Non-elevated } \\
\text { neurotic symptoms } \\
\text { Male } \\
\text { White ethnicity } \\
\text { Any home } \\
\text { ownership status } \\
\text { Number of } \\
\text { qualifications }\end{array}$ \\
\hline Cooper et $a^{\beta 2}$ & Cross-sectional & $\begin{array}{l}\text { Adult Psychiatric } \\
\text { Morbidity Survey }\end{array}$ & $\begin{array}{l}\text { UK residents (some } \\
\text { with CMPs) }\end{array}$ & 22196 & $\begin{array}{l}16+(\mathrm{M} \text { not } \\
\text { stated })\end{array}$ & 52 & 19 & $\begin{array}{l}\text { - PCT attendance } \\
\text { - GP contact for }\end{array}$ & $\begin{array}{l}\text { Aged } 35-54 \\
\text { Aged } 75+\end{array}$ & $\begin{array}{l}\text { Aged } 16-34 \\
\text { Aged } 55-74\end{array}$ \\
\hline
\end{tabular}




\begin{tabular}{|c|c|c|c|c|c|c|c|c|c|c|}
\hline \multirow[b]{2}{*}{ Study } & \multirow[b]{2}{*}{ Design } & \multirow[b]{2}{*}{ Data source } & \multicolumn{4}{|l|}{ Participants } & \multirow[b]{2}{*}{ Q ST } & \multirow[b]{2}{*}{ HSU outcomes } & \multirow[b]{2}{*}{ Predictors of increased HSU } & \multirow{2}{*}{$\begin{array}{l}\text { Not predictive of } \\
\text { increased HSU }\end{array}$} \\
\hline & & & Composition & $\mathbf{N}$ & Age & Per cent $f$ & & & & \\
\hline & & Adult avchiotrir & & & & & & $\begin{array}{l}\text { GP contacts } \\
\text { Group PCT } \\
\text { attendances } \\
\text { Home carer visits } \\
\text { Inpatient admissions } \\
\text { Inpatient days } \\
\text { Non-psychiatric } \\
\text { outpatient attendances } \\
\text { Nurse contacts } \\
\text { - Occupational therapist } \\
\text { contacts } \\
\text { Psychiatric outpatient } \\
\text { attendances } \\
\text { Psychiatrist contacts } \\
\text { Psychologist contacts } \\
\text { - Sheltered workshop } \\
\text { attendances } \\
\text { Specialist education } \\
\text { attendances } \\
\text { Total inpatient service } \\
\text { use }\end{array}$ & & - $\mathrm{Nl} \mathrm{OCD}$ diannocis \\
\hline Torres et $a^{\beta 9}$ & Cross-sectional & $\begin{array}{l}\text { Adult sychiatric } \\
\text { morbidity survey }\end{array}$ & UK residents with $\mathrm{OCD}$ & 114 & $\begin{array}{l}16-74 \\
\text { (M not } \\
\text { stated) }\end{array}$ & 65 & 13 & $\begin{array}{l}\text { Any community service } \\
\text { attendance } \\
\text { Counselling attendance } \\
\text { - GP contact for } \\
\text { psychological problems } \\
\text { - Home carer visits } \\
\text { - Medication usage } \\
\text { - PCT attendance } \\
\text { - Psychiatric inpatient } \\
\text { admission } \\
\text { - Community psychiatric } \\
\text { nurse contacts } \\
\text { - Psychiatric outpatient } \\
\text { attendances } \\
\text { Psychiatrist contact } \\
\text { - Psychologist contact } \\
\text { - Support group } \\
\text { attendances } \\
\text { - Total HSU ('any kind of } \\
\text { treatment') }\end{array}$ & $\begin{array}{l}\text { OCD diagnosis } \\
\text { OCD with comorbid anxiety or } \\
\text { depression }\end{array}$ & - No OCD diagnosis \\
\hline $\begin{array}{l}\text { Ullrich and } \\
\text { Coid }^{40}\end{array}$ & Cross-sectional & $\begin{array}{l}\text { Adult Psychiatric } \\
\text { Morbidity Survey }\end{array}$ & $\begin{array}{l}\text { UK residents with } \\
\text { ASPD }\end{array}$ & 245 & $\begin{array}{l}16-74(\mathrm{M} \\
\text { not stated })\end{array}$ & 22 & 16 & $\begin{array}{l}\text { Community psychiatric } \\
\text { nurse contacts } \\
\text { GP contacts } \\
\text { - Other nursing service } \\
\text { contacts } \\
\text { - Outreach worker } \\
\text { contacts } \\
\text { Psychiatric inpatient } \\
\text { admission } \\
\text { - Psychiatrist contacts }\end{array}$ & $\begin{array}{l}\text { Comorbid Axis } 1 \text { mental } \\
\text { disorders }\end{array}$ & $\begin{array}{l}\text { Comorbid } \\
\text { personality disorders }\end{array}$ \\
\hline
\end{tabular}




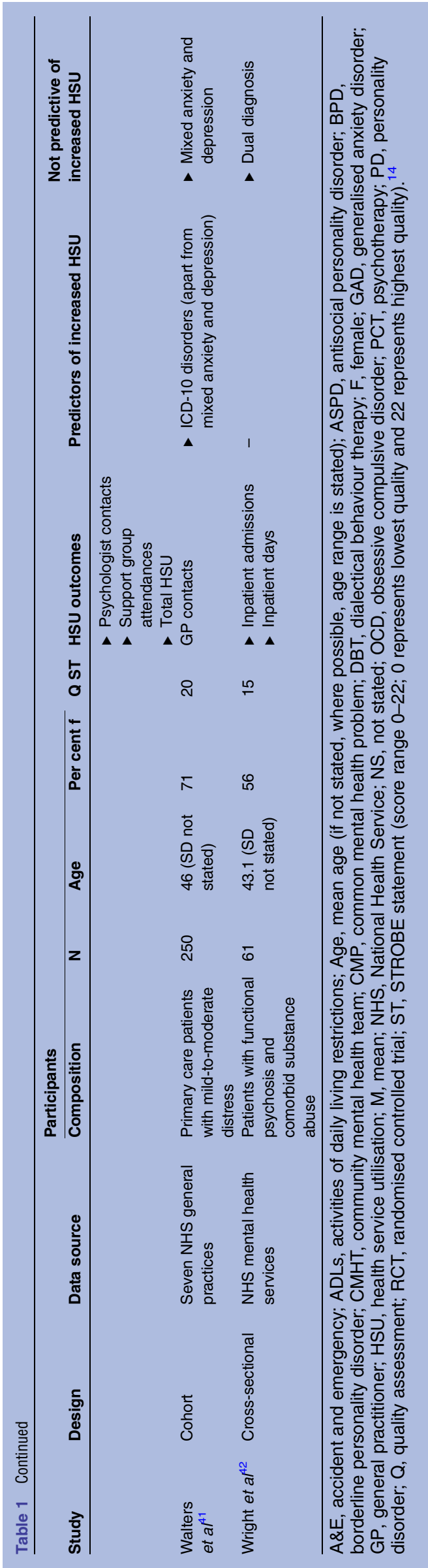

with HSU. ${ }^{4}$ Thereafter, health service providers receive a fixed payment based on the cluster each patient is allocated to, with clusters with higher expected HSU generating higher payments than those with lower expected HSU. ${ }^{5}$ Paying providers fixed payments based on 'clustering' of treated patients allows policymakers to distribute resources in a systematic and equitable manner. ${ }^{3}$

In recent years, there have been ongoing efforts by the National Health Service (NHS) in England to develop (a potential UK-wide) activity-based payment system for its mental health services, in what is referred to as Mental Health Payment by Results. Initially, the system will cover secondary care services with various service types excluded (eg, those relating to primary care psychotherapy, acquired brain injury and autism). ${ }^{6}$ A subject of much debate in this development surrounds how to define 'mental health clusters' for use in this system. In contrast to typical activity-based payment systems, diagnostic information has so far not been used to define these clusters. Instead, clusters have been defined using the newlydeveloped Mental Health Clustering Tool (MHCT). The MHCT assesses the domains of behaviour, symptoms, impairment, social functioning and risk factors, and is used to assign patients to one of 21 clusters, falling under one of three broad 'super-classes' (non-psychotic, psychotic and organic). ${ }^{7}$

One of the main reasons for not using diagnostic information for clustering in Mental Health Payment by Results was that mental disorder diagnosis was shown to be a poor predictor of HSU in studies involving national and multisite trial data sets. ${ }^{8-11}$ On the other hand, it has been argued that although mental disorder diagnosis alone is not sufficient for clustering purposes, information about broad diagnoses and care pathways can be combined, in a simple and practical manner, to form reliable clusters with homogenous resource patterns. ${ }^{12}$ Moreover, the MHCT has also been criticised because its development did not take HSU and costs into account, ${ }^{13}$ and, currently, very little evidence exists for the ability of the MHCT to predict HSU in patient populations.

In the context of the ongoing development of Mental Health Payment by Results, and the debate surrounding the use of diagnostic information and the MHCT, it is important to provide evidence that can inform decisions about which variables might be used to derive mental health clusters. To date, no UK-based systematic reviews informing this process have been undertaken. A review of relevant studies set in the UK would address UK-specific HSU patterns, increasing the applicability of findings to the Mental Health Payment by Results system. Therefore, the general objective of this systematic review is to identify variables with sufficient evidence supporting their ability to predict HSU. The review has two specific aims. First, to identify the variables examined in relation to the prediction of HSU by adults with mental disorders in the UK. Second, to determine the level of evidence that exists for identified predictors of this HSU. 


\section{METHOD}

\section{Inclusion and exclusion criteria}

Only the following types of studies were included in the review: (1) observational and intervention studies that predicted HSU by adults with mental disorders. (For the purposes of this review, mental disorders included adults experiencing elevated symptoms of mental disorders or adults formally diagnosed with a mental disorder. Studies with participants with intellectual disability were excluded due to the specific additional needs of this population that have to be met beyond the healthcare system, eg, in the education or labour systems); (2) studies based in the UK, with UK participants; (3) peerreviewed studies published in scientific journals, in the year 2000 or after. (This cut-off point was chosen so that included studies were approximately in line with the overall Payment by Results scheme introduced in 2003. Intervention costing studies that did not predict HSU were excluded).

\section{Literature search}

Based on these criteria, the first author searched four databases: PsycINFO, CINAHL Plus with full text, MEDLINE and EMBASE. The final search was conducted on 25 March 2014. Additional records were identified from manually searching reference lists of included studies. Search terms and database subject headings related to HSU (ie, health care utilisation [subject heading] OR health care utili* OR health service utili* OR health care use OR health service use) were combined with those terms for mental disorders (ie, Mental disorders [subject heading] OR psychiatric) and the UK location (ie, UK [subject heading) OR NHS). Owing to the differing search procedures deployed by the four databases, slightly altered versions of this search strategy were used in each database. Independent screening of $20 \%$ of abstracts was undertaken by the third author. When the first author and third author disagreed regarding the screening outcome of an abstract, the abstract was included in screening at 'full-text' level (by the first author).

\section{Data extraction}

Data from included studies were extracted using an Excel spreadsheet. Extracted data pertained to basic study description, study design, records source, data collection times, participants, mental disorder investigated, operationalisation of HSU outcomes, the prediction of HSU and statistics. In addition, each study was assessed for quality using the STROBE statement ${ }^{14}$ (for observational studies) and the National Institute for Health and Clinical Excellence (NICE) checklist for Randomised Controlled Trials (RCTs). ${ }^{15}$ The former is a checklist of 22 items related to the reporting of title (one item), introduction (two items), methods (nine items), results (five items), discussion (four items) and funding information (one item). ${ }^{14}$ The latter assesses bias in RCTs in four sections: selection bias, performance bias, attrition bias and detection bias. ${ }^{15}$

\section{Data analysis}

Owing to the heterogeneity in study designs, samples and mental disorders investigated, a meta-analysis was not possible. Narrative synthesis was deemed the most appropriate method of data analysis.

\section{RESULTS}

\section{Literature search flow}

The literature search flow is displayed in figure 1. In total, 1364 records were identified. Database-searching yielded 1347 records and manually searching yielded 17 additional records. After duplicates were removed, 928 studies were screened at 'abstract' level. For screening of abstracts, there was a $94.1 \%$ agreement rate between the first author and the third author. After abstract screening, 133 studies were assessed for eligibility at 'full-text' level. Twenty-eight studies were included in the final review.

\section{Overview of included studies}

To provide an overview of included studies, extracted data were summarised in two tables (tables 2 and 3). Table 2 summarises observational studies of HSU, and table 3 summarises studies of interventions (of both observational and experimental design) aiming to reduce HSU. As can be seen in both tables, the data source of included studies varied. Most frequently, it included routine NHS service data or databases $(n=14)$, different versions of the Adult National Psychiatric Morbidity Survey $(\mathrm{n}=6)$ and other household and postal surveys $(n=3)$. The sample composition also varied and included adults with a psychotic disorder $(\mathrm{n}=7)$, personality disorder $(n=5)$, depression $(n=3)$, an anxiety disorder $(n=2)$, an eating disorder $(n=1)$, 'common mental health problems' $(n=2)$ and dementia $(n=1)$. It also included health service users $(n=6)$ and former adolescent psychiatric patients $(n=1)$. The quality of included studies was mixed. STROBE statement ${ }^{14}$ scores for observational studies $(\mathrm{n}=25)$ ranged from 9 to 20 (mean $(\mathrm{M})$ $=15.5 ; \mathrm{SD}=3.05$ ), out of a possible maximum score of 22 . Of the three RCTs assessed using the NICE checklist, ${ }^{15}$ two indicated the absence of bias, and one indicated the possible presence of bias. As can be seen in tables 2 and 3, both the operationalisation of HSU outcomes and the identified predictors of HSU in individual studies varied widely.

\section{Operationalisation of HSU outcomes}

To determine the level of evidence for identified predictors of HSU, it was beneficial to first summarise the operationalisation of HSU outcomes across included studies. This summary is provided in table 1 . Across the 28 studies, 60 different HSU outcome variables were assessed 155 times in total: 24 of these related to 


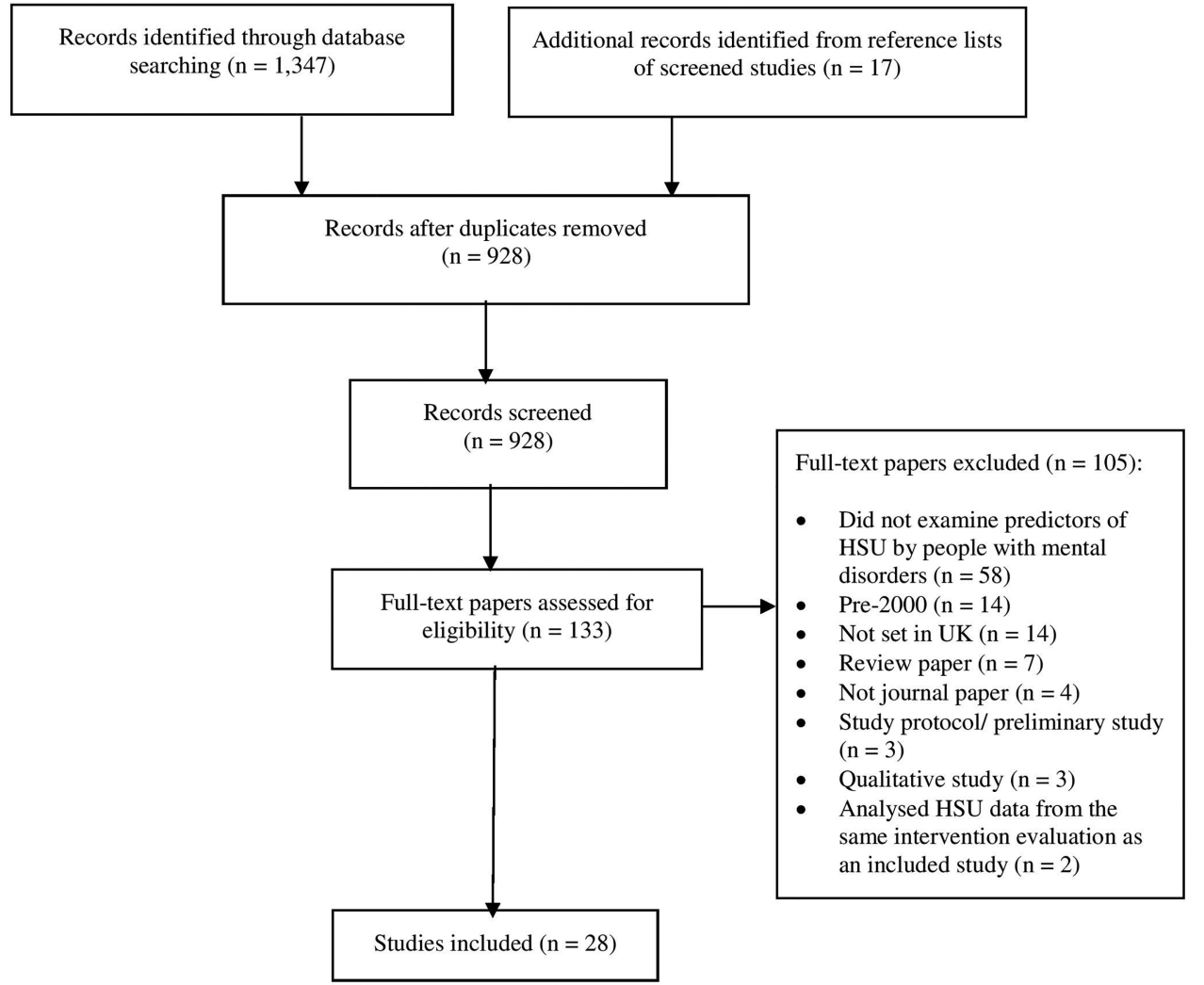

Figure 1 Literature search flow.

primary care $\mathrm{HSU}, 79$ to specialist HSU, 40 to inpatient HSU and 12 to 'total and other' HSU. Across all categories apart from the 'total and other' HSU category, 65 outcomes related to mental health HSU and 78 related to general health HSU.

HSU outcomes used in three or more studies were: medication usage $(n=12)$; inpatient days $(n=9)$; accident and emergency (A \& E) admissions $(\mathrm{n}=8)$; inpatient admissions $(n=8)$; total HSU $(n=8)$; GP contacts $(n=7)$; GP contacts for psychological problems $(n=6)$; psychotherapy attendances $(n=6)$; community psychiatric nurse contacts $(\mathrm{n}=5)$; psychiatrist contacts $(\mathrm{n}=5)$; psychiatric inpatient admissions $(n=5)$; psychologist contacts $(n=5)$; nurse contacts $(n=4)$; outpatient attendances $(n=4)$; counsellor contacts $(n=3)$; and home carer visits $(n=3)$. Remaining HSU outcomes are shown in table 1.

\section{Summary of evidence for identified predictors of HSU}

Table 4 provides a summary of the evidence for identified predictors of HSU. The table is structured as follows. First, identified predictors are categorised by 'demographics', 'diagnosis', 'interventions', 'symptoms', 'functioning' and 'behaviour'. Second, the table displays the number of times each identified predictor variable was assessed in relation to HSU, and the number of times each identified variable significantly predicted HSU (and vice versa). Third, using the broad categories of 'primary care HSU', 'specialist HSU', 'inpatient HSU' and 'total HSU', the table documents the operationalisation of HSU outcomes in relation to the prediction of HSU. Fourth, study quality information is provided to aid evaluation of the evidence. For simplicity, a study was arbitrarily deemed to be of 'satisfactory' quality if it scored $>16$ on the STROBE statement, ${ }^{14}$ or if bias was not present on three out of four domains on the NICE checklist for RCTs. ${ }^{15}$

As an overview, the review identified 31 predictor variables that were examined in relation to the prediction of HSU. By category, these were: 12 demographic variables, six intervention variables, five diagnostic variables, four symptom variables, three functioning variables and one behavioural variable.

The 12 demographic variables significantly predicted increased HSU 41 of 65 times assessed (63.1\%). Six demographic variables predicted increased HSU in two or more assessments and in over $50 \%$ of assessments made. These variables, in order of frequency of increased HSU prediction, were: comorbidity (both mental and physical), age (heterogeneous age ranges), female gender, a marital status of divorced, separated or widowed, non-white ethnicity and high previous HSU. Regarding the age variable, several heterogeneous age ranges (eg, 35-54, 31-49, 35+, 50-64) were associated with increased HSU, thus it was not possible to draw conclusions relating to specific age ranges. Specific age ranges associated with increased HSU in individual studies are viewable in table 2 . As study quality was satisfactory in the vast majority of these assessments, it can be concluded that good preliminary evidence exists for 


\begin{tabular}{lll} 
Study & Design & Data source \\
\hline Amner $^{43}$ & Cohort & NHS service data
\end{tabular}

Participants

Patients with BPD availing of DBT

2136.2

$(\mathrm{SD}=10.87)$

81

ST NC HSU outcomes

- Day care attendances

- DBT attendances

- Nurse contacts

- Outpatient attendances

- PCT attendances

\begin{tabular}{|c|c|c|c|c|c|c|c|c|c|c|c|c|}
\hline Ballard et $a f^{44}$ & $\begin{array}{l}\text { Quasi- } \\
\text { experi-mental }\end{array}$ & Care facilities & Patients with dementia & 224 & $\begin{array}{l}82.5 \\
(S D=7.1)\end{array}$ & 75 & 12 & - & $\begin{array}{l}\text { - Total HSU } \\
\text { - GP contacts } \\
\text { - Inpatient days }\end{array}$ & Psychiatric liaison & Usual care & YES \\
\hline Bateman $^{45}$ & RCT & NHS PD PCT unit & Patients with BPD & 41 & $\begin{array}{l}31.8 \\
(\mathrm{SD}=6.23)\end{array}$ & 58 & - & 2 & $\begin{array}{l}\text { A\&E attendances } \\
\text { Outreach worker } \\
\text { contacts } \\
\text { - Inpatient days } \\
\text { - Medication usage } \\
\text { PCT attendances } \\
\text { - Psychiatric treatment } \\
\text { days }\end{array}$ & $\begin{array}{l}\text { Mentalisation-based } \\
\text { treatment by partial } \\
\text { hospitalisation }\end{array}$ & Usual care & YES \\
\hline $\begin{array}{l}\text { Comman-der } \\
\text { et } a f^{46}\end{array}$ & Cohort & $\begin{array}{l}\text { Assertive outreach } \\
\text { service data }\end{array}$ & $\begin{array}{l}\text { Outreach patients with } \\
\text { schizophrenia, bipolar } \\
\text { disorder or 'other' } \\
\text { disorder }\end{array}$ & 250 & $\begin{array}{l}18-64(M \\
\text { not stated) }\end{array}$ & 26 & 12 & - & $\begin{array}{l}\text { - Compulsory admissions } \\
\text { - Inpatient admissions } \\
\text { Inpatient days }\end{array}$ & $\begin{array}{l}\text { Community outreach } \\
\text { service use }\end{array}$ & - & YES \\
\hline $\begin{array}{l}\text { de Lusignan } \\
\text { et } a \uparrow^{47}\end{array}$ & Cohort & $\begin{array}{l}\text { NHS (IAPT and } \\
\text { hospital service) data }\end{array}$ & IAPT attendees & 1118 & $\begin{array}{l}35.3 \\
(S D=21.4)\end{array}$ & 50 & 15 & - & $\begin{array}{l}\text { A\&E attendances } \\
\text { Inpatient admissions } \\
\text { Inpatient days } \\
\text { - Medication usage } \\
\text { Outpatient attendances } \\
\text { - Sick notes issued }\end{array}$ & IAPT service & - & YES \\
\hline $\begin{array}{l}\text { de Lusignan } \\
\text { et } a f^{48}\end{array}$ & Case control & $\begin{array}{l}\text { NHS (IAPT and } \\
\text { hospital service) data }\end{array}$ & $\begin{array}{l}\text { IAPT attendees with } \\
\text { long-term health } \\
\text { conditions }\end{array}$ & 1341 & $\begin{array}{l}52.8 \\
(\mathrm{SD}=11.15)\end{array}$ & 65 & 19 & - & $\begin{array}{l}\text { A\&E attendances } \\
\text { Inpatient admissions } \\
\text { Inpatient days } \\
\text { - Medication usage } \\
\text { Outpatient attendances } \\
\text { - Sick notes issued }\end{array}$ & IAPT service & - & YES \\
\hline $\begin{array}{l}\text { Hayhurst } \\
\text { et }\left.a\right|^{49}\end{array}$ & Cohort & $\begin{array}{l}\text { NHS University } \\
\text { hospitals service data }\end{array}$ & $\begin{array}{l}\text { Patients receiving } \\
\text { antipsychotic medication }\end{array}$ & 126 & $\begin{array}{l}42.55 \\
(S D=12.29)\end{array}$ & 35 & 16 & - & $\begin{array}{l}\text { Inpatient admissions } \\
\text { - Inpatient days }\end{array}$ & Clozapine & - & YES \\
\hline Lam et $a^{50}$ & $\mathrm{RCT}$ & $\begin{array}{l}\text { Maudsley \& Bethlem } \\
\text { NHS trust area }\end{array}$ & $\begin{array}{l}\text { Patients with bipolar } \\
\text { disorder }\end{array}$ & 87 & $\begin{array}{l}43.95 \\
(S D=11.45)\end{array}$ & 33 & - & 4 & $\begin{array}{l}\text { Any community services } \\
\text { attendance } \\
\text { Medication usage } \\
\text { - Non-psychiatric inpatient } \\
\text { days } \\
\text { - Psychiatric inpatient } \\
\text { days } \\
\text { - Total HSU }\end{array}$ & $\begin{array}{l}\text { Cognitive therapy (added } \\
\text { to usual care) }\end{array}$ & Usual care & NO \\
\hline Shi et $a^{51}$ & Cohort & $\begin{array}{l}\text { NHS primary care } \\
\text { database }\end{array}$ & $\begin{array}{l}\text { Depressed adults } \\
\text { initiating duloxetine }\end{array}$ & 909 & $\begin{array}{l}49.6 \\
(S D=16.5)\end{array}$ & 67 & 17 & - & $\begin{array}{l}\text { A\&E attendances } \\
\text { Inpatient admissions } \\
\text { - Medication usage } \\
\text { - Referrals to specialists }\end{array}$ & Duloxetine & - & YES \\
\hline Wade et $a^{F^{2}}$ & Cohort & $\begin{array}{l}\text { NHS primary care } \\
\text { database }\end{array}$ & $\begin{array}{l}\text { Depressed adults using } \\
\text { escitalopram, }\end{array}$ & 2485 & $\begin{array}{l}43.1 \\
(S D=14.7)\end{array}$ & 60 & 18 & - & $\begin{array}{l}\text { - GP phone calls } \\
\text { GP visits } \\
\text { - Inpatient admissions }\end{array}$ & Escitalopram & $\begin{array}{l}\text { Generic } \\
\text { SSRls; } \\
\text { venla-faxine }\end{array}$ & YES \\
\hline
\end{tabular}




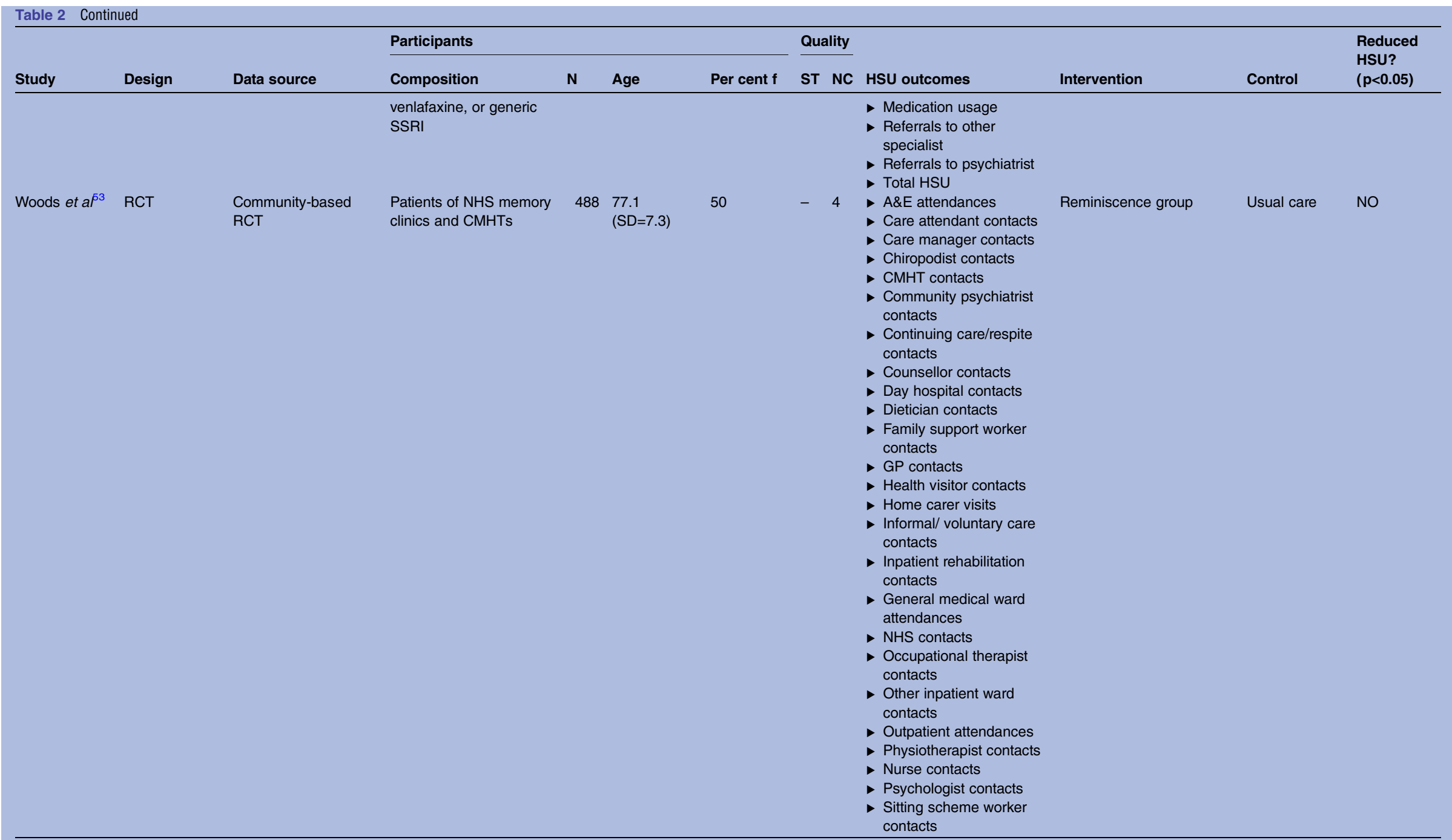

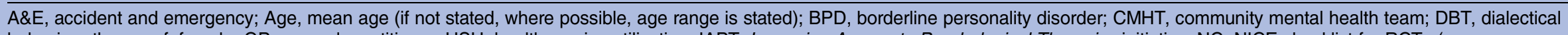
behaviour therapy; f, female; GP, general practitioner; HSU, health service utilisation; IAPT, Improving Access to Psychological Therapies initiative; NC, NICE checklist for RCTs (score range $=0-4 ; 0$ indicates bias and 4 indicates no bias) (NICE, 2009); NHS, National Health Service; PD, personality disorder; ST, STROBE statement (score range 0-22; 0 represents lowest quality and 22 represents highest quality) (14); PCT=psychotherapy. 
these six demographic variables in relation to the prediction of increased HSU.

The six intervention variables significantly predicted decreased HSU 10 of 17 times assessed (58.8\%). Two intervention variables predicted decreased HSU in two or more assessments and in over $50 \%$ of assessments made. These variables, in order of frequency of decreased HSU prediction, were: accessing an Improving Access to Psychological Therapies (IAPT) service and medication. As study quality was satisfactory in all but one of these assessments (an assessment of IAPT), it can be concluded that good preliminary evidence exists for both IAPT and medication in relation to the prediction of decreased HSU.

The five diagnostic variables significantly predicted increased HSU 13 of 15 times assessed (86.6\%). Two diagnostic variables predicted increased HSU in two or more assessments and in over $50 \%$ of assessments made. These variables, in order of frequency of increased HSU prediction, were: personality disorder and obsessive compulsive disorder. Whereas all (eight) assessments of personality disorder came from studies of satisfactory quality, none of the (four) assessments of obsessive compulsive disorder came from studies of satisfactory quality. Therefore, it can only be concluded that good preliminary evidence exists for personality disorder in relation to the prediction of increased HSU.

The four symptom variables significantly predicted increased HSU 7 of 15 times assessed (46.6\%). One symptom variable-neurotic symptoms-predicted increased HSU in six of six assessments made. Although two assessments came from studies of unsatisfactory quality, it can be concluded that good preliminary evidence exists for neurotic symptoms in relation to the prediction of increased HSU.

The three functioning variables significantly predicted increased HSU five of nine times assessed (55.6\%). Two functioning variables predicted increased HSU in two or more assessments and in over $50 \%$ of assessments made. These variables, in order of frequency of increased HSU prediction, are: cognitive deficits and activities of daily living (ADLs). Whereas all (two) assessments of ADLs came from studies of satisfactory quality, none of the (three) assessments of cognitive deficits came from studies of satisfactory quality. Therefore, it can only be concluded that good preliminary evidence exists for ADLs in relation to the prediction of increased HSU.

In the final variable category, a behavioural variableself-harm-significantly predicted increased HSU once, of the one time assessed. This assessment came from a study of satisfactory quality. However, as just one assessment was undertaken, it cannot be concluded that good preliminary evidence exists for self-harm in relation to the prediction of increased HSU.

In summary, taking into account frequency of prediction and study quality, several predictor variables have good preliminary evidence supporting their ability to predict HSU by adults with mental disorders in the UK. Of these variables (in order of frequency of prediction), comorbidity, personality disorder, age (heterogeneous age ranges), neurotic symptoms, female gender, a marital status of divorced, separated or widowed, non-white ethnicity, high previous HSU and activities of daily living, were associated with increased HSU. Moreover, good preliminary evidence was found for associations of accessing a primary care psychological treatment service and medication use with decreased HSU. Figure 2 illustrates the relative frequencies of predictors of HSU, by category.

\section{DISCUSSION}

\section{Summary of main findings}

Taking into account study quality, 28 studies identified a range of variables with good preliminary evidence supporting their ability to predict HSU. Of these variables, comorbidity, personality disorder, age (heterogeneous age ranges), neurotic symptoms, female gender, a marital status of divorced, separated or widowed, nonwhite ethnicity, high previous HSU and activities of daily living, were associated with increased HSU. Moreover, good preliminary evidence was found for associations of accessing a primary care psychological treatment service and medication use with decreased HSU.

\section{Comparison of main findings with other reviews}

Few existing reviews of the predictors of HSU in mental health populations were available for comparison of results. Nevertheless, comorbidity-the most evidenced predictor of increased HSU in the present review-was also shown in a review of 72 studies to predict increased psychiatric service utilisation by 'heavy users' of psychiatric services. ${ }^{16}$ This previous review found that several variables not examined by studies in our review (ie, substance abuse, psychotic illness, isolation, homelessness and social support) were predictive of increased psychiatric service utilisation. In line with the present review, another review of eight studies found that high previous utilisation predicted increased psychiatric service utilisation. ${ }^{17}$ On the other hand, this review found that the variables of living alone and psychosis diagnosis-not examined by studies in the present review-were predictive of increased psychiatric service utilisation.

Overall, the findings from previous reviews add robustness to our finding of good preliminary evidence for the variables of comorbidity and high previous HSU in relation to the prediction of increased HSU by adults with mental disorders in the UK. In addition, despite the sole focus of the previous reviews on psychiatric services, which limits their comparability, it is possible that several additional variables-in particular, a psychosis diagnosis -may also predict increased HSU by adults with mental disorders in the UK.

\section{Comparison of main findings with international studies of HSU}

As the review was limited to UK studies, it is informative to compare the findings with those from international 
Table 3 Frequency of HSU outcomes used across included studies $(n=28)$

\begin{tabular}{|c|c|c|c|c|c|}
\hline Primary care HSU & $\mathrm{n}$ & General health* & & Compulsory admissions & 1 \\
\hline Mental health & & Nurse contacts & 4 & Psychiatric treatment days & 1 \\
\hline $\begin{array}{l}\text { GP contact(s) for psychological } \\
\text { problems }\end{array}$ & 6 & Home carer visits & 3 & Total & 9 \\
\hline Referrals to psychiatrist & 1 & Any community service attendance & 2 & & \\
\hline Support group attendances & 2 & General medical ward attendances & 2 & General health* & \\
\hline \multirow[t]{2}{*}{ Total } & 9 & Occupational therapist contacts & 2 & Inpatient days & 9 \\
\hline & & Outreach worker contacts & 2 & A\&E attendances & 8 \\
\hline General health* & & Care attendant contacts & 1 & Inpatient admissions & 8 \\
\hline GP contacts & 7 & Care manager contacts & 1 & Non-psychiatric inpatient days & 2 \\
\hline GP phone calls & 2 & Chiropodist contacts & 1 & Sheltered workshop attendances & 1 \\
\hline GP visits & 2 & Continuing care /respite contacts & 1 & Sitting scheme worker contacts & 1 \\
\hline Referrals to specialists & 2 & Counselling attendance & 1 & Specialist education attendances & 1 \\
\hline Sick notes issued & 2 & Day hospital contacts & 1 & Total inpatient service use & 1 \\
\hline \multirow[t]{2}{*}{ Total } & 15 & Dietician contacts & 1 & Total & 31 \\
\hline & & Family support worker contacts & 1 & & \\
\hline Specialist HSU & $\mathrm{n}$ & Health visitor contacts & 1 & Total and other HSU & $\mathrm{n}$ \\
\hline Mental health & & Informal/voluntary care contacts & 1 & Total HSU & 8 \\
\hline Medication usage $†$ & 12 & Inpatient rehabilitation contacts & 1 & Other' HSU & 1 \\
\hline Psychotherapy attendance(s) & 6 & NHS contacts & 1 & $\begin{array}{l}\text { Any service use for psychological } \\
\text { problem }\end{array}$ & 1 \\
\hline Community psychiatric nurse contacts & 5 & $\begin{array}{l}\text { Non-psychiatric outpatient } \\
\text { attendances }\end{array}$ & 1 & Client Services Receipt Inventory & 2 \\
\hline Psychiatrist contact(s) & 5 & Other inpatient ward contacts & 1 & Total & 12 \\
\hline Psychologist contact(s) & 5 & Other nursing service contacts & 1 & & \\
\hline Outpatient attendances & 4 & Other specialist contacts & 1 & Summary totals & $\mathrm{n}$ \\
\hline Counsellor contacts & 3 & Physiotherapist contacts & 1 & Primary Care HSU & 24 \\
\hline Day care attendances & 2 & Total & 32 & Specialist HSU & 79 \\
\hline $\mathrm{CMHT}$ contacts & 2 & & & Inpatient HSU & 40 \\
\hline DBT attendances & 1 & Inpatient HSU & $\mathrm{n}$ & Total and other HSU & 12 \\
\hline Psychiatric outpatient attendances & 1 & Mental health & & Mental health HSU & 65 \\
\hline Psychologist/psychiatrist contacts & 1 & Psychiatric inpatient admission(s) & 5 & General health HSU & 78 \\
\hline \multirow[t]{2}{*}{ Total } & 47 & Psychiatric inpatient days & 1 & Types of outcome variables & 60 \\
\hline & & Psychiatric outpatient attendances & 1 & Times outcomes assessed & 155 \\
\hline
\end{tabular}

studies of HSU by adults with mental disorders. Three recent international studies were chosen for comparative purposes because of their large samples comprising adults with a range of mental health problems. ${ }^{18-20}$

The first was set in Canada, and had a sample of 243 adults diagnosed with various mental disorders. ${ }^{18}$ In line with our review, it found that increased social withdrawal, female gender and (mental disorder) comorbidity were associated with increased HSU. Additional predictors of increased HSU not identified by studies in our review were emotional problems, income, major depression diagnosis and alcohol dependence.

The second study was set in Australia and had a sample of 822 adults who had previously participated in a school-based epidemiological study in their youth. ${ }^{19}$ In line with our review, it found that age (treated as continuous variable), comorbidity and a marital status of divorced, were associated with increased HSU. Additional predictors of increased HSU not identified by studies in our review were psychological distress, affective disorder diagnosis and exposure to childhood trauma, while rural living predicted reduced HSU.
The third study ${ }^{20}$ used data from a cross-national health survey and involved 8688 adults from the USA and Canada. It found that comorbidity (various health comorbidities), female gender and non-white ethnicity, were associated with increased HSU. Additional predictors of increased HSU not identified by studies in our review were emotional problems, income, having a regular doctor and having insurance.

The findings from these international studies add robustness to our finding of good preliminary evidence for the variables of comorbidity, female gender and a marital status of divorced, in relation to the prediction of HSU by adults with mental disorders in the UK. In addition, it is possible that several additional variables identified in international studies-in particular, emotional problems-may also predict HSU by adults with mental disorders in the UK.

\section{Implications of findings for mental health payment by results}

Our findings can inform the debate surrounding the use of diagnostic information and the MHCT for clustering purposes. The findings also highlight several 


\begin{tabular}{|c|c|c|c|c|c|c|c|c|c|c|c|c|c|c|c|c|c|c|c|c|c|c|c|c|c|c|c|}
\hline \multirow[b]{5}{*}{ Predictor variables } & \multirow{5}{*}{$\begin{array}{l}n \text { variable } \\
\text { assessed }\end{array}$} & \multicolumn{13}{|c|}{ Assessments in which variable predicted HSU } & \multicolumn{13}{|c|}{ Assessments in which variable did not predict HSU } \\
\hline & & \multirow[b]{4}{*}{$\mathbf{n}$} & \multicolumn{12}{|c|}{ HSU outcomes predicted $(n)^{*}$} & & \multicolumn{12}{|c|}{ HSU outcomes not predicted $(\mathbf{n})^{*}$} \\
\hline & & & \multicolumn{3}{|c|}{ Primary care } & \multicolumn{3}{|c|}{ Specialist } & \multicolumn{3}{|c|}{ Inpatient } & \multicolumn{3}{|c|}{ Total HSU } & & \multicolumn{3}{|c|}{ Primary care } & & ialis & & & ient & & & IHS & \\
\hline & & & & & & & Que & & & & & & & & & & & & & & & & & & & & \\
\hline & & & $\mathbf{n}$ & + & - & $\mathbf{n}$ & + & - & $\mathbf{n}$ & + & - & $\mathbf{n}$ & + & - & $\mathbf{n}$ & $\mathbf{n}$ & + & - & $\mathbf{n}$ & + & - & $\mathbf{n}$ & + & - & $\mathbf{n}$ & + & - \\
\hline Demographic $^{28-373940}$ & & & & & & & & & & & & & & & & & & & & & & & & & & & \\
\hline Comorbidity $\dagger$ & 15 & 14 & 4 & 3 & 1 & 3 & 2 & 1 & 3 & 2 & 1 & 4 & 2 & 2 & 1 & 0 & & & 0 & & & 1 & 0 & 1 & 0 & & \\
\hline Age $\ddagger$ & 7 & 7 & 2 & 2 & 0 & 2 & 2 & 0 & 2 & 1 & 1 & 1 & 1 & 0 & 0 & & & & & & & & & & & & \\
\hline Female gender & 7 & 5 & 2 & 2 & 0 & 2 & 2 & 0 & 1 & 1 & 0 & 0 & & & 2 & 0 & & & 0 & & & 1 & 0 & 1 & 1 & 1 & 0 \\
\hline Male gender & 7 & 2 & 0 & & & 0 & & & 1 & 1 & 0 & 1 & 1 & 0 & 5 & 2 & 2 & 0 & 2 & 2 & 0 & 1 & 0 & 1 & 0 & & \\
\hline NW ethnicity & 6 & 4 & 2 & 2 & 0 & 2 & 2 & 0 & 0 & & & 0 & & & 2 & 0 & & & 0 & & & 0 & & & 2 & 1 & 1 \\
\hline White ethnicity & 6 & 1 & 0 & & & 0 & & & 0 & & & 1 & 0 & 1 & 5 & 2 & 2 & 0 & 2 & 2 & 0 & 0 & & & 1 & 1 & 0 \\
\hline Marital status§ & 5 & 4 & 2 & 2 & 0 & 2 & 2 & 0 & 0 & & & 0 & & & 1 & 0 & & & 0 & & & 0 & & & 1 & 0 & 1 \\
\hline Non-home owner & 5 & 2 & 1 & 1 & 0 & 1 & 1 & 0 & 0 & & & 0 & & & 3 & 1 & 1 & 0 & 1 & 1 & 0 & 0 & & & 1 & 0 & 1 \\
\hline Qualifications & 3 & 0 & 0 & & & 0 & & & 0 & & & 0 & & & 3 & 1 & 1 & 0 & 1 & 1 & 0 & 0 & & & 1 & 0 & 1 \\
\hline High prev HSU & 2 & 2 & 0 & & & 0 & & & 0 & & & 2 & 2 & 0 & 0 & 0 & & & 0 & & & 0 & & & 0 & & \\
\hline Family situation & 1 & 0 & 0 & & & 0 & & & 0 & & & 0 & & & 1 & 0 & & & 0 & & & 1 & 0 & 1 & 0 & & \\
\hline Occupation & 1 & 0 & 0 & & & 0 & & & 0 & & & 0 & & & 1 & 0 & & & 0 & & & 1 & 0 & 1 & 0 & & \\
\hline Total & 65 & 41 & 13 & 12 & 1 & 12 & 11 & 1 & 7 & 5 & 2 & 9 & 6 & 3 & 24 & 6 & 6 & 0 & 6 & 6 & 0 & 5 & 0 & 5 & 7 & 3 & 4 \\
\hline Intervention $\prod^{43-53}$ & & & & & & & & & & & & & & & & & & & & & & & & & & & \\
\hline IAPT service & 4 & 4 & 1 & 1 & 0 & 1 & 1 & 0 & 2 & 1 & 1 & 0 & & & 0 & 0 & & & 0 & & & 0 & & & 0 & & \\
\hline Psychotherapy & 4 & 1 & 1 & 1 & 0 & 0 & & & 0 & & & 0 & & & 3 & 0 & & & 1 & 1 & 0 & 1 & 1 & 0 & 1 & 1 & 0 \\
\hline Reminiscence grp & 4 & 0 & 0 & & & 0 & & & 0 & & & 0 & & & 4 & 1 & 1 & 0 & 1 & 1 & 0 & 1 & 1 & 0 & 1 & 1 & 0 \\
\hline Medication & 3 & 3 & 1 & 1 & 0 & 0 & & & 2 & 2 & 0 & 0 & & & 0 & 0 & & & 0 & & & 0 & & & 0 & & \\
\hline Comm outreach & 1 & 1 & 0 & & & 0 & & & 1 & 1 & 0 & 0 & & & 0 & 0 & & & 0 & & & 0 & & & 0 & & \\
\hline Psychiatric liaison & 1 & 1 & 1 & 0 & 1 & 0 & & & 0 & & & 0 & & & 0 & 0 & & & 0 & & & 0 & & & 0 & & \\
\hline Total & 17 & 10 & 4 & 3 & 1 & 1 & 1 & 0 & 5 & 4 & 1 & 0 & & & 7 & 1 & 1 & 0 & 2 & 2 & 0 & 2 & 2 & 0 & 2 & 2 & 0 \\
\hline Diagnostic $^{26} 29303941$ & & & & & & & & & & & & & & & & & & & & & & & & & & & \\
\hline PD & 8 & 8 & 2 & 2 & 0 & 2 & 2 & 0 & 2 & 2 & 0 & 2 & 2 & 0 & 0 & 0 & & & 0 & & & 0 & & & 0 & & \\
\hline $\mathrm{OCD}$ & 4 & 4 & 1 & 0 & 1 & 1 & 0 & 1 & 1 & 0 & 1 & 1 & 0 & 1 & 0 & 0 & & & 0 & & & 0 & & & 0 & & \\
\hline Unspec ICD-10 & 1 & 1 & 1 & 1 & 0 & 0 & & & 0 & & & 0 & & & 0 & 0 & & & 0 & & & 0 & & & 0 & & \\
\hline Eating disorder & 1 & 0 & 0 & & & 0 & & & 0 & & & 0 & & & 1 & 0 & & & 0 & & & 0 & & & 1 & 0 & 1 \\
\hline MADD & 1 & 0 & 0 & & & 0 & & & 0 & & & 0 & & & 1 & 1 & 1 & 0 & 0 & & & 0 & & & 0 & & \\
\hline Total & 15 & 13 & 4 & 3 & 1 & 3 & 2 & 1 & 3 & 2 & 1 & 3 & 2 & 1 & 2 & 1 & 1 & 0 & 0 & & & 0 & & & 1 & 0 & 1 \\
\hline Symptoms ${ }^{31-34} 38$ & & & & & & & & & & & & & & & & & & & & & & & & & & & \\
\hline Neurotic & 6 & 6 & 3 & 2 & 1 & 2 & 2 & 0 & 0 & & & 1 & 0 & 1 & 0 & 0 & & & 0 & & & 0 & & & 0 & & \\
\hline Depression & 4 & 0 & 0 & & & 0 & & & 0 & & & 0 & & & 4 & 1 & 0 & 1 & 1 & 0 & 1 & 1 & 0 & 1 & 1 & 0 & 1 \\
\hline Positive ${ }^{\star *}$ & 4 & 0 & 0 & & & 0 & & & 0 & & & 0 & & & 4 & 1 & 0 & 1 & 1 & 0 & 1 & 1 & 0 & 1 & 1 & 0 & 1 \\
\hline Insomnia & 1 & 1 & 1 & 1 & 0 & 0 & & & 0 & & & 0 & & & 0 & 0 & & & 0 & & & 0 & & & 0 & & \\
\hline $\begin{array}{l}\text { Total } \\
\text { Functioning } \\
3138\end{array}$ & 15 & 7 & 4 & 3 & 1 & 2 & 2 & 0 & 0 & & & 1 & 0 & 1 & 8 & 2 & 0 & 2 & 2 & 0 & 2 & 2 & 0 & 2 & 2 & 0 & 2 \\
\hline Social withdrawal & 4 & 0 & 0 & & & 0 & & & 0 & & & 0 & & & 4 & 1 & 0 & 1 & 1 & 0 & 1 & 1 & 0 & 1 & 1 & 0 & 1 \\
\hline Cognitive deficits & 3 & 3 & 1 & 0 & 1 & 1 & 0 & 1 & 1 & 0 & 1 & 0 & & & 0 & 0 & & & 0 & & & 0 & & & 0 & & \\
\hline ADLs & 2 & 2 & 1 & 1 & 0 & 1 & 1 & 0 & 0 & & & 0 & & & 0 & 0 & & & 0 & & & 0 & & & 0 & & \\
\hline Total & 9 & 5 & 2 & 1 & 1 & 2 & 1 & 1 & 1 & 0 & 1 & 0 & & & 4 & 1 & 0 & 1 & 1 & 0 & 1 & 1 & 0 & 1 & 1 & 0 & 1 \\
\hline Behavioural $^{35}$ & & & & & & & & & & & & & & & & & & & & & & & & & & & \\
\hline Self-harm & 1 & 1 & 0 & & & 0 & & & 1 & 1 & 0 & 0 & & & 0 & 0 & & & 0 & & & 0 & & & 0 & & \\
\hline
\end{tabular}

${ }^{*}$ Most studies examined more than one health service utilisation outcome measure.

†Both mental and physical comorbidity.

Various heterogeneous age ranges predicted increased HSU in individual studies: $16-34 ; 31-49 ; 45-54 ;$ 50-64; >35; 35-54; $75+$.

$\S$ Only divorced/separated/widowed marital statuses were predictive of increased HSU.

Ilf an intervention reduced HSU, it was counted as predicting HSU and vice versa.

**Positive=positive symptoms associated with schizophrenia.

ADLs, activities of daily living; Comm, community; grp, group; HSU, health service utilisation; IAPT, Improving Access to Psychological Therapies initiative; ICD-10, International Classification of Diseases-10; MADD

mixed anxiety and depressive disorder; NW, non-White; PD, personality disorder; prev, previous; Prim, Primary; Unspec, Unspecified +=A score of $>16$ on STROBE statement, ${ }^{14}$ or $>3$ on NICE checklist for RCTs; ${ }^{15}$

$-=$ A score of $<15$ on STROBE checklist, or <2 on NICE RCT checklist). 


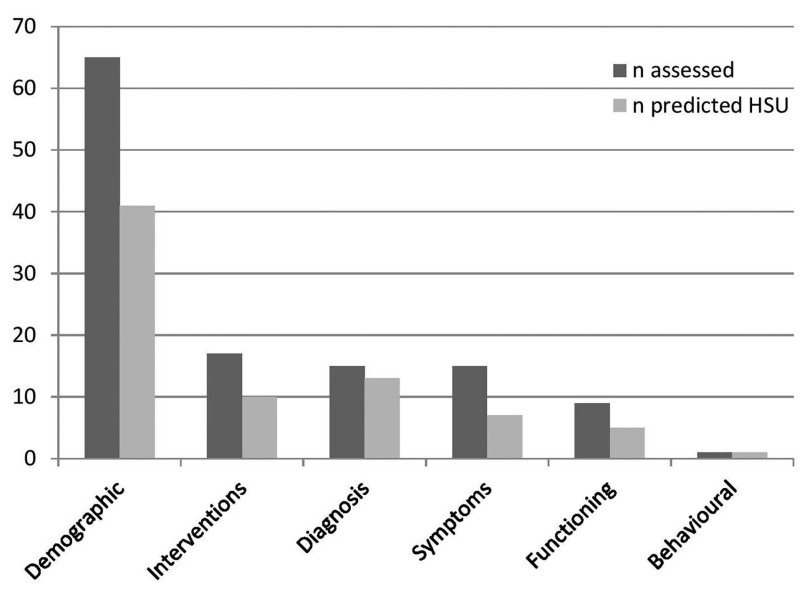

Figure 2 Frequency of HSU prediction by variable category. HSU, health service utilisation; frequencies were obtained by counting some studies various times for one variable category; for interventions, the count concerned the prediction of decreased HSU.

additional variables that are worthy of consideration in the clustering process.

Regarding the use of diagnostic information, in contrast to previous large-scale studies, which showed mental disorder diagnosis to be a poor predictor of increased HSU, ${ }^{9-11}$ the review yielded good preliminary evidence for personality disorder diagnosis in relation to the prediction of increased HSU. In addition, it is noted that diagnoses of psychosis, major depression and affective disorder, were identified as predictors in previous reviews and international studies. ${ }^{16-19}$ Although methodological differences (eg, in the operationalisation of HSU) in these reviews and studies mean that firm conclusions cannot be drawn, a possible explanation for the discrepancy in findings is that some but not other mental disorder diagnoses may be significantly associated with increased HSU. The uncertainty regarding the ability of mental disorder diagnoses to predict increased HSU means that this review neither refutes nor supports the argument that reliable mental health clusters can be formed by combining broad diagnoses with care pathways, in a simple and practical manner. ${ }^{12}$

Findings relating to the domains of the MHCT (ie, behaviour, symptoms, impairment, social functioning and risk factors) can aid assessments of its suitability for clustering purposes. Although some variables relating to these domains were examined, good preliminary evidence for the prediction of increased HSU was found for just two relevant variables-neurotic symptoms and ADLs. Therefore, this review does not provide sufficient evidence to settle the debate regarding the use of the MHCT. However, it highlights the need for further investigation of the link between the MHCT and increased HSU, especially since this link was not taken into account in the initial development of the MHCT. ${ }^{13}$

Regarding additional variables worth considering in the clustering process, various demographic (ie, comorbidity, age, female gender, marital status, nonwhite ethnicity, high previous HSU) and intervention (ie, IAPT, medication) variables with good preliminary evidence relating to their ability to predict HSU were identified. Future research could investigate if adding these variables into the 'case mix' of the MHCT adds to the economic validity and reliability of mental health clusters. However, it is worth noting that variables that are predictive of HSU are not always suitable for clustering and resource allocation purposes. For example, concerning demographic variables, it could be argued that it would be unfair to distribute resources on the basis of increased HSU by females (relative to males). Similar arguments could be made regarding other population groupings with contrasting HSU levels (eg, certain ethnic groups). Moreover, the benefit of using intervention variables for clustering purposes may be somewhat limited because it is relatively easy for providers to use these variables to 'game' the system (ie, when patients are inappropriately and deliberately allocated to clusters that attract higher fixed payments) in order to generate additional revenue. ${ }^{7}$

\section{Methodological considerations}

There is relevant research relating to HSU by people with mental disorders not included in this review. This was for various methodological reasons, for example, differing conceptualisations of HSU in investigations by Killapsy and $\mathrm{Zi}^{21}$ and Trieman and Leff. ${ }^{22}$ These studies focused on the stability of HSU over time, and were excluded because they do not address our study question, which concerns identifying predictive variables contributing to an increase or decrease in HSU. In addition, various methodological factors should be taken into account when interpreting our findings. First, the quality of included studies was mixed. Specifically, using arbitrarily cut-off points on the STROBE statement $^{14}$ and the NICE checklist for RCTs, ${ }^{15} 18$ of the 28 studies $(64.2 \%)$ were deemed to be of 'satisfactory' quality. This mixed quality limits the strength of conclusions that can be drawn. Second, there was wide heterogeneity in the operationalisation of HSU by included studies, which limits the validity of comparisons across studies. A possible reason for this heterogeneity is that 23 out of $28(82 \%)$ studies collected secondary data from NHS service databases or household surveys, and thus their operationalisation of HSU was constrained. Addressing this issue, the operationalisation of HSU in included studies was documented in considerable detail (table 1). Third, the review was limited to UK studies, meaning the list of identified variables is not exhaustive, and the findings may not be applicable to services in other countries. Indeed, this applicability is particularly limited given that only a few other countries (eg, Australia, New Zealand, Canada, the Netherlands, Norway, USA) have made progress implementing mental health payment systems, using heterogeneous clustering and resource distribution methodologies. ${ }^{23}$ Fourth, the 
majority of literature searching was undertaken by one study author. However, in order to minimise bias and error, $20 \%$ of abstracts were independently screened by another author. Fifth, the age variable was reported with heterogeneous age ranges across studies. Thus, conclusions in relation to specific age ranges could not be made. Finally, the study benefits from its thorough reporting process and use of structured checklists for assessments of study quality.

\section{Additional future research directions}

Five future research directions not already discussed in relation to Mental Health Payment by Results are provided. First, as the operationalisation of HSU in included studies was largely constrained by the use of secondary data from service databases, future HSU studies may benefit from the administration of measures such as the Client Services Receipt Inventory, ${ }^{24}$ alongside secondary data. Second, an international systematic review of the predictors of HSU by mental health populations could provide a more comprehensive list of predictor variables. Third, the HSU of people with intellectual disabilities was not examined in this review due to the specific additional needs of this population that have to be met beyond the healthcare system. However, it is an important area of research since UK-based studies have highlighted the widespread failure of health services to make required additional accommodations (eg, extended appointment hours) for this patient group, with no additional funding currently allocated for these purposes to NHS acute trusts. ${ }^{25}$ Determining how the inadequate provision of additional accommodations impacts on the HSU of people with intellectual disabilities could inform future decisions surrounding allocation of resources. Fourth, the review identified a number of variables (ie, attending a community outreach service, attending a psychiatric liaison service, unspecified International Classification of Diseases Tenth Edition (ICD-10) diagnosis, insomnia symptoms, self-harming behaviour) examined in relation to HSU in just one study yet predictive of HSU. Therefore, the associations of these variables with HSU could be explored in future research. Finally, further large-scale case register studies (including participants from shared service catchment areas) would address the study heterogeneity found in this review and provide more robust evidence on the predictors of HSU by people with mental disorders in the UK.

\section{CONCLUSIONS}

This review provides evidence that can inform decisions about which variables might be used to derive mental health clusters in the Mental Health Payment by Results system. Several variables-in particular, comorbidity, female gender, age (heterogeneous age ranges) high previous HSU and a marital status of divorced-have good preliminary evidence supporting their ability to predict HSU by adults with mental disorders in the UK, and thus are relevant for clustering purposes. The findings support the need to determine the association of the MHCT (and its domains of behaviour, symptoms, impairment, social functioning and risk factors) with HSU, the need to investigate whether combining broad diagnoses with care pathways is an effective alternative method for mental health clustering, and the need for research to further examine the association between existing mental health clusters and HSU. Overall, this review has highlighted important unresolved issues related to the Mental Health Payment by Results system. Addressing these issues could improve how health service resources are distributed, helping to ensure that people experiencing mental health problems can access the most appropriate services at their time of need.

\section{Author affiliations}

${ }^{1}$ Faculty of Social and Human Sciences, University of Southampton,

Southampton, UK

${ }^{2}$ Faculty of Medicine, University of Southampton, Southampton, UK

${ }^{3}$ Swiss Paraplegic Research, Nottwil, Switzerland

${ }^{4}$ Department of Health Sciences \& Health Policy, University of Lucerne, Lucerne, Switzerland

${ }^{5}$ Faculty of Social and Human Sciences, School of Psychology, University of Southampton, UK

${ }^{6}$ Department of Medical Informatics, Biometry and Epidemiology—IBE, Research Unit for Biopsychosocial Health, Ludwig-Maximilians-University (LMU), Munich, Germany

${ }^{7}$ Swiss Paraplegic Research, Nottwil, Switzerland

Contributors CDT, AC and DSB conceived the paper. CDT and AC designed the paper, and undertook analysis and interpretation of data. CDT drafted the paper. MH and DSB inputted into the literature search process. All authors critically reviewed the paper and suggested revisions. All authors gave final approval for the paper for submission.

Funding The research is funded by the People Programme (Marie Curie Actions) of the European Union's Seventh Framework Programme FP7/20072013/ (REA grant agreement $n^{\circ} 316795$ ).

Competing interests None declared.

Provenance and peer review Not commissioned; externally peer reviewed.

Data sharing statement No additional data are available.

Open Access This is an Open Access article distributed in accordance with the Creative Commons Attribution Non Commercial (CC BY-NC 4.0) license, which permits others to distribute, remix, adapt, build upon this work noncommercially, and license their derivative works on different terms, provided the original work is properly cited and the use is non-commercial. See: http:// creativecommons.org/licenses/by-nc/4.0/

\section{REFERENCES}

1. van Essen AM. New hospital payment systems: comparing medical strategies in The Netherlands, Germany and England. J Health Organ Manag 2009;23:304-18.

2. Street A, Maynard A. Activity based financing in England: the need for continual refinement of payment by results. Health Econ Policy Law 2007;2(Pt 4):419-27.

3. Busse R, Schreyögg J, Smith PC. Editorial: hospital case payment systems in Europe. Health Care Manag Sci 2006;9:211-13.

4. Mathauer I, Wittenbecher F. Hospital payment systems based on diagnosis-related groups: experiences in low- and middle-income countries. Bull World Health Organ 2013;91:746-56A.

5. Marini G, Street A. The administrative costs of payment by results. Univeristy of York, 2007.

6. NHS. Mental Health Payment by Results Guidance for 2013-14. Leeds: NHS, 2013. 
7. Macdonald AJ, Elphick M. Combining routine outcomes measurement and 'Payment by Results': will it work and is it worth it? Br J Psychiatry 2011;199:178-9.

8. Macdonald A, Elphick M. Care clusters and mental health payment by results (author's reply). Br J Psychiatry 2012;200:163.

9. Elphick M, Antony P. Casemix groupings for psychiatry: strengths and weaknesses of 'Version 2.0 Healthcare Resource Groups' (HRGs). J Ment Health (Abingdon, England) 1996;5:443-50.

10. English JT, Sharfstein SS, Scherl DJ, et al. Diagnosis-related groups and general hospital psychiatry: the APA study. Am J Psychiatry 1986;143:131-9.

11. Schumacher DN, Namerow MJ, Parker B, et al. Prospective payment for psychiatry-feasibility and impact. N Engl J Med 1986;315:1331-6.

12. Kingdon D, Solomka B, McAllister-Williams $\mathrm{H}$, et al. Care clusters and mental health payment by results. Br J Psychiatry 2012;200:162.

13. Bekas S, Michev O. Payment by results: validating care cluster allocation in the real world. Psychiatry 2013;37:349-55.

14. von Elm E, Altman DG, Egger M, et al. The Strengthening the Reporting of Observational Studies in Epidemiology (STROBE) statement: guidelines for reporting observational studies. J Clin Epidemiol 2008;61:344-9.

15. NICE. The guidelines manual. London: NICE, 2009

16. Kent S, Fogarty M, Yellowlees P. A review of studies of heavy users of pyschiatric services. Psychiatr Serv 1995;46:1247-53.

17. Hansson L, Sandlund M. Utilization and patterns of care in comprehensive psychiatric care organizations. A review of studies and some methodological considerations. Acta Psychiatr Scand 1992;86:255-61.

18. Fleury MJ, Grenier G, Bamvita JM, et al. Determinants and patterns of service utilization and recourse to professionals for mental health reasons. BMC Health Serv Res 2014;14:161.

19. Mills V, Van Hooff M, Baur J, et al. Predictors of mental health service utilisation in a non-treatment seeking epidemiological sample of Australian adults. Community Ment Health J 2012;48:511-21.

20. Vasiliadis HM, Lesage A, Adair CE, et al. Do Canada and the United States differ in prevalence of depression and utilization of services? Psychiatr Serv 2007;58:63-71.

21. Killaspy H, Zis P. Predictors of outcomes for users of mental health rehabilitation services: a 5-year retrospective cohort study in inner London, UK. Soc Psychiatry Psychiatr Epidemiol 2013;48:1005-12.

22. Trieman $\mathrm{N}$, Leff $\mathrm{J}$. Long-term outcome of long-stay psychiatric in-patients considered unsuitable to live in the community. $\mathrm{Br}$ Psychiatry 2002;181:428-32.

23. Mason A, Goddard M, Myers L, et al. Navigating uncharted waters? How international experience can inform the funding of mental health care in England. J Ment Health 2011;20:234-48.

24. Beecham J, Knapp M. Costing psychiatric interventions. In: Thornicroft G, Brewin C, Wing JK, eds. Measuring mental health needs. 2nd edn. London: Gaskell, 2001:163-83.

25. Tuffrey-Wijne I, Goulding L, Giatras N, et al. The barriers to and enablers of providing reasonably adjusted health services to people with intellectual disabilities in acute hospitals: evidence from a mixed-methods study. BMJ Open 2014;4:e004606.

26. Button EJ, Benson E, Nollett C, et al. Don't forget EDNOS (eating disorder not otherwise specified): patterns of service use in an eating disorders service. Psychiatry Bull 2005;29:134-6.

27. Byford S, Barrett B, Despiégel N, et al. Impact of treatment success on health service use and cost in depression: longitudinal database analysis. Pharmacoeconomics 2011;29:157-70.

28. Chollet J, Saragoussi D, Clay E, et al. A clinical research practice datalink analysis of antidepressant treatment patterns and health care costs in generalized anxiety disorder. Value Health 2013;16:1133-9.

29. Coid J, Yang M, Bebbington P, et al. Borderline personality disorder: health service use and social functioning among a national household population. Psychol Med 2009;39:1721-31.

30. Coid J, Yang M, Tyrer P, et al. Prevalence and correlates of personality disorder in Great Britain. Br J Psychiatry 2006:188:423-31.

31. Cooper C, Bebbington $\mathrm{P}, \mathrm{McM}$ anus $\mathrm{S}$, et al. The treatment of common mental disorders across age groups: results from the 2007 Adult Psychiatric Morbidity Survey. J Affect Disord 2010;127:96-101.
32. Cooper C, Spiers N, Livingston G, et al. Ethnic inequalities in the use of health services for common mental disorders in England. Soc Psychiatry Psychiatr Epidemiol 2013;48:685-92.

33. Foster K, Meltzer H, Gill B, et al. The circumstances of adults with a psychotic disorder. Int Rev Psychiatry 2003;15:84-90.

34. Hayward R, Jordan KP, Croft P. Healthcare use in adults with insomnia: a longitudinal study. Br J Gen Pract 2010;60:334-40.

35. Keene J, Rodriguez J. Are mental health problems associated with use of accident and emergency and health-related harm? Eur $J$ Public Health 2007:17:387-93.

36. Knapp M, McCrone P, Fombine E, et al. The Maudsley long-term follow-up of child and adolescent depression: 3. Impact of comorbid conduct disorder on service use and costs in adulthood. $\mathrm{Br} J$ Psychiatry 2002;180:19-23.

37. Mohan R, McCrone P, Szmukler G, et al. Ethnic differences in mental health service use among patients with psychotic disorders. Soc Psychiatry Psychiatr Epidemiol 2006;41:771-6.

38. Patel A, Everitt B, Knapp M, et al. Schizophrenia patients with cognitive deficits: factors associated with costs. Schizophr Bull 2006;32:776-85.

39. Torres AR, Prince MJ, Bebbington PE, et al. Treatment seeking by individuals with obsessive-compulsive disorder from the British Psychiatric Morbidity Survey of 2000. Psychiatr Serv 2007:58:977-82.

40. Ullrich S, Coid J. Antisocial personality disorder: co-morbid Axis I mental disorders and health service use among a national household population. Pers Mental Health 2009;3:151-64.

41. Walters K, Buszewicz M, Weich S, et al. Mixed anxiety and depressive disorder outcomes: prospective cohort study in primary care. Br J Psychiatry 2011;198:472-8.

42. Wright S, Gournay K, Glorney E, et al. Dual diagnosis in the suburbs: prevalence, need, and in-patient service use. Soc Psychiatry Psychiatr Epidemiol 2000;35:297-304.

43. Amner K. The effect of DBT provision in reducing the cost of adults displaying the symptoms of BPD. British J Psychotherapy 2012;28:336-52.

44. Ballard C, Powell I, James I, et al. Can psychiatric liaison reduce neuroleptic use and reduce health service utilization for dementia patients residing in care facilities? Int J Geriatr Psychiatry 2002:17:140-5.

45. Bateman A, Fonagy P. 8-Year follow-up of patients treated for borderline personality disorder: mentalization-based treatment versus treatment as usual. Am J Psychiatry 2008;165:631-8.

46. Commander M, Sashidharan S, Rana T, et al. North Birmingham assertive outreach evaluation. Patient characteristics and clinical outcomes. Soc Psychiatry Psychiatr Epidemiol 2005;40:988-93.

47. de Lusignan S, Chan T, Parry G, et al. Referral to a new psychological therapy service is associated with reduced utilisation of healthcare and sickness absence by people with common mental health problems: a before and after comparison. $J$ Epidemiol Community Health 2012;66:1-6.

48. de Lusignan S, Chan T, Tejerina Arreal MC, et al. Referral for psychological therapy of people with long term conditions improves adherence to antidepressants and reduces emergency department attendance: controlled before and after study. Behav Res Ther 2013:51:377-85.

49. Hayhurst KP, Brown P, Lewis SW. The cost-effectiveness of clozapine: a controlled, population-based, mirror-image study. J Psychopharmacol 2002;16:169-75.

50. Lam DH, McCrone $\mathrm{P}$, Wright $\mathrm{K}$, et al. Cost-effectiveness of relapse-prevention cognitive therapy for bipolar disorder: 30-month study. Br J Psychiatry 2005;186:500-6.

51. Shi N, Cao Z, Durden E, et al. Healthcare utilization among patients with depression before and after initiating duloxetine in the United Kingdom. J Med Econ 2012;15:672-80.

52. Wade AG, Saragoussi D, Despiegel N, et al. Healthcare expenditure in severely depressed patients treated with escitalopram, generic SSRIs or venlafaxine in the UK. Curr Med Res Opin 2010;26:1161-70.

53. Woods RT, Bruce E, Edwards RT, et al. REMCARE: reminiscence groups for people with dementia and their family caregiverseffectiveness and cost-effectiveness pragmatic multicentre randomised trial. Health Technol Assess 2012;16:v-xv, 1-116. 